\title{
LAS MUJERES Y LA REVOLUCIÓN MEDIÁTICA: UNA DE LAS BASES DE LAS REVUELTAS Y DEL CAMBIO EN EL MUNDO ÁRABE
}

\author{
José María Perceval Verde y Núria Simelio Solà \\ Universitat Autònoma de Barcelona \\ josepmaria.perceval@uab.cat - nuria.simelio.sola@uab.cat
}

Recibido: 28-02-2011

Aceptado: 21-03-2011

\section{Resumen}

En este artículo analizamos la participación de las mujeres en las revueltas árabes, específicamente en Túnez y Egipto, de finales del año 2010 y principios del 2011. El proceso de cambio político y social impulsado por una población juvenil deseosa de instaurar un sistema democrático no pude ser entendida sin tener en cuenta la gran participación femenina en las protestas. La masiva participación sin precedentes inmediatos de las mujeres en este proceso, tanto en la organización como en la preparación y realización, fue posible gracias a los cambios mediáticos de los últimos cinco años. El artículo realiza un recorrido que muestra como la variación de la imagen de la mujer ha sido determinante en esta novedosa implicación de las mujeres árabes en las revoluciones sociales. Esta transformación se produce tanto en los medios tradicionales a partir de los programas de entretenimiento y en la ficción, como en las redes satelitales de información y esencialmente en las redes sociales por Internet y los blogs que han revolucionado totalmente el panorama mediático del mundo árabe.

Palabras Clave: Mujeres activistas, revueltas árabes, mujeres en el mundo árabe, redes sociales, medios de comunicación árabes.

\begin{abstract}
This article analyses the women's role in the Arab revolutions, specifically in Tunisia and Egypt, from latest 2010 to early 2011. The process of social and political change that has been driven by youth men and women, who demanded a democratic system, can't be understood without taking into account the substantial feminine participation on the protests. The unprecedented number of women who participated in the preparation, organization and carrying out of this process, was possible thanks to the
\end{abstract}


media changes of the last five years. This article explains how the change of the women's image has been a deciding factor in this newly implication of the Arab women in the social revolutions. This transformation was generated on the traditional mainstream media (entertainment programmes and the shows), on the information from the satellite televisions and essentially on the social networking and the blogs that have completely changed the media system of the Arabic World.

Keywords: Women's activism, Arab protests, women in the Arab world, social networking, Arab mass media.

\section{Introducción}

La mujer árabe ha vivido un cambio radical en los últimos años que ha sido ocultado, invisibilizado o negado por los medios occidentales ayudados por gran parte de los propios del mundo árabe y por un apoyo académico importante. Sin embargo, las perspectivas han cambiado a raíz de las revueltas del norte de África. El mundo árabe ha vuelto a ser llamado por su nombre - mundo árabe- dejando el término arabo-musulmán (o musulmán a secas) de tan sólo hace unos meses. Esto no significa que el islam haya desaparecido sino que, momentáneamente, vuelve a ocupar su lugar: la religión que practica la mayoría de la población del mundo árabe (donde también hay cristianos y agnósticos).

Liberados, pues, de esta losa previa y constringente, un doble cambio de paradigma nos puede ayudar a comprender el nuevo panorama de la mujer en el mundo árabe. Un cambio que supere los esquemas diferencialistas del multiculturalismo y los esquemas islamófobos disfrazados de defensa de los derechos humanos (y femeninos) desde una perspectiva absolutamente homogeneizadora. Es decir, un cambio que nos lleve a oponer el interculturalismo incluyente y solidario frente al multiculturalismo diferencialista y que nos lleve a repensar una nueva visión mucho más pragmática de los derechos individuales sin dejar de pensar que son inalienables y universales (Chaker, 2004).

Hay que superar viejos esquemas asimismo en las formas. Podemos encontrar muchas feministas con hiyab (Stratton, 2009) o feministas profundamente religiosas en el mundo árabe, lo que contrasta aparentemente con el modelo occidental de liberación. (Abul-Magd, Perrier, 2006). Sobre todo, tenemos que aceptar el gradualismo y la liberación interna, no impuesta por salvacionistas exteriores.

Superadas estas trabas iniciales, -que no han desaparecido pero que se encuentran atenuadas-, es más fácil introducirse en el estudio de la situación de la mujer 
en el mundo árabe, su relación con los medios, su lucha contra el patriarcalismo y explicarse de algún modo su gran participación en las recientes revueltas.

\section{El cambio del panorama mediático y la mujer}

La prensa y la radio tradicional han sido un espacio predominantemente público y masculino en el mundo árabe especialmente desde la creación de la radio árabe por Nasser, donde se jerarquizaban las voces masculinas a partir de la autoridad que daba tanto el medio como las estrategias narrativas utilizadas (Labidi, K., 2003).

La radio había tenido una influencia notable por el poco desarrollo de la comunicación impresa que aún se encuentra en una relación de 1 a 6 con los países industrializados y, también, por el carácter bilingüe de la comunicación impresa (en árabe y en inglés o francés) lo que provoca un filtro de origen colonial con la lengua hablada. Según James, (James, 2006) el éxito de la radio egipcia Sawt al-Arab (1952) preludió un espacio de opinión común al mundo árabe con mayor calado que la prensa en árabe. Al mismo tiempo, la radio comenzó una progresiva e inevitable destrucción de la cultura oral al introducir en las casas y en los campos - gracias al transistor - una voz autorizada y ajena a la familia y las jerarquías locales. Actualmente, la radio se ha convertido en el mayor difusor de modas y comportamientos, de expresiones y maneras de hablar, de nuevos ritmos y ha propiciado un sincretismo musical que afecta a todo el mundo arabo-musulmán con préstamos evidentes entre países pero con figuras locales poderosas. La radio comenzó a cambiar contraponiendo al lenguaje de las prédicas de los viernes una expresión coloquial directa de los discman norteamericanos a los que imitaban al mismo tiempo que renovaba el éxito de las radios europeas de entreguerras con mensajes y discos dedicados. Estos discman utilizan un lenguaje lleno de giros humorísticos y de ironías, de chistes y pequeños relatos que inciden muchas veces en críticas sociales pero también ahondan en estereotipos sociales o étnicos (Perceval, 2007).

La radio ha sido la 'culpable' de la introducción del hip-hop que abarca desde Marruecos a Palestina, con fuertes resistencias en los sectores radicales islamistas o nacionalistas árabes pero con un evidente éxito juvenil. Fue muy interesante en ese sentido, el congreso de 2003 del Goethe Institut en Dakar donde se analizó los mass

media de Senegal desde las radios a la prensa local, o la penetración de modelos externos y la intervención del poder (Taureg, Wittmann, 2003). También en este congreso, se mostró como desde el comienzo hasta la actualidad, la radio ha sido 
fuertemente controlada y censurada por el poder, sus comentaristas responden a consignas muy concretas y, por eso, ha sido el campo musical el más libre aunque ciertos grupos están vetados por sus letras críticas del sistema. El rap y sus variedades rompen la tradición de canciones amorosas e introduce los temas sociales, la ironía y, a veces, el insulto directo a los dirigentes corruptos, los falsos religiosos beatos y los empresarios explotadores (Perceval, 2007).

Por su parte, la televisión cambió en su momento el panorama radicalmente al aumentar la influencia mediática con su enorme capacidad de seducción y, culturalmente, al adoptar modelos claramente occidentales: look de presentadores y presentadoras representación femenina inédita en muchos casos, modas de los entrevistados, presencia constante de invitados e imágenes occidentales, publicidad de productos occidentales en un marco claramente occidental (Kraidy, 2002). La presencia de occidente aumentó por la presión de los films que se emiten en televisión (anglófonos o francófonos, según el área de colonización) y por las imágenes de agencia, absolutamente dominadas por occidente. (Nisbet, M.; Nisbet, D, Scheufele y Shanahan, 2004).

La segunda revolución comunicativa y posterior a la de la radio, se produce con la emergencia de las cadenas televisivas árabes, desde comienzos de los años ochenta, que aumentan la producción propia y comienzan el desarrollo del mercado regional que compite débilmente en principio con los productos occidentales. Según, ElNawawy y Iskandar (2007), la cadena al-Yazira es un medio cuya audiencia en principio $-\mathrm{y}$ posiblemente hasta el comienzo de las revueltas -es mayoritariamente masculina (pero menos que la CNN en su origen). Las mujeres se unen a la audiencia en los momentos en que hay conflictos - aunque con menos minutos que los varones.

Sin embargo, el formato $\mathrm{CNN} / \mathrm{BBC}$ de la cadena qatarí si cambia algunos esquemas al situar presentadoras de la cadena (aunque no directoras o conductoras de los grandes programas de debate, reservados a los hombres y con una participación absoluta de varones entre los invitados) (Lamloum, 2006).

Por razones de competitividad, las cadenas locales que intentan competir con las nuevas televisiones satelitales, introducen programas de entretenimiento, humor y ficción que si tienen un amplio público femenino. Series del ramadán y grandes telenovelas. Son programas con una gran influencia de Bollywood que justifican en muchos casos el amor y el matrimonio arreglado pero donde ciertos aspectos del patriarcalismo son puestos en cuestión (Armbrust, 1998).

En el humor es el campo donde la imagen de una nueva mujer ha avanzado más. Los ataques al integrismo religioso y el patricarcalismo (Fargues, 2003), son constantes en los humoristas, incluso en Arabia Saudí. Los humoristas al no poder hacer 
crítica política han aumentado las referencias a los temas sociales lo que ha beneficiado a la lucha por la igualdad de sexo, en el trabajo o en las decisiones familiares, claramente puestas en cuestión. Algunos de los temas que han tratado son la elección de pareja frente al matrimonio arreglado, la posibilidad de expresión femenina, el trabajo doméstico, etc. (Hadan, 2005).

Los formatos europeos de la telebasura (incluidas imitaciones de Fama o de Gran Hermano) a pesar de los problemas que conllevan, también se han introducido junto a los típicos concursos. Esto ha mostrado, la competitividad y la individualidad ganadora, que son nuevos valores en alza en una sociedad mucho más individualista. Aunque la mujer participa menos en estos programas, son los varones los que arrasan como participantes, las cifras de audiencia son mayoritariamente femeninas.

Es sobre este nuevo panorama mediático que se insertan los blogs y las redes sociales (Fauad, 2010) desde el Atlántico al Indico reafirmando la unidad de este nuevo espacio (Eickelman y Anderson, 1999) pero, al mismo tiempo, con características nacionales particulares (Alavi, 2005).

\section{Situación de la mujer en los nuevos formatos}

En los nuevos formatos televisivos del mundo árabe, principalmente en los programas de entretenimiento, de humor y en las telenovelas, cada vez más se simboliza a una mujer que toma decisiones y acertadamente, que habla y con razón, que actúa en contra de las decisiones del poder masculino. Estos tres aspectos, aun contando con antecedentes, son novedosos. La mujer víctima o traidora, madre sacrificada o prostituta, sigue apareciendo pero compitiendo con la nueva imagen que -al ganar audiencia de forma considerable en razón del nuevo público femenino de los mediashace que los guionistas la primen sobre los antiguos esquemas narrativos (sin abandonarlos del todo).

El humor es ambiguo. En el caso del mundo arabo-musulmán tenemos una enorme constatación de la presencia del humor y la ironía en la vida cotidiana y como elemento clave en la comunicación de personas y grupos. La mayoría de los asuntos se tratan con una fuerte dosis de humor y de argumentaciones irónicas, sobre todo en el pequeño comercio, por la costumbre aun arraigada del regateo.

El problema a la hora de analizarlo estriba en que los estudios sobre el humor árabe están centrados en formas y prácticas de tipo clásico (trabajos sobre literatura y 
tradición como el género humorístico Adab). Los chistes circulan en SMS o se venden en CDs en los mercados, por todo el mundo arabo-islámico, casi todos de tradición clásica pero donde se introducen nuevos relatos o nuevas versiones de los mismos con temas como la guerra de Irak o el problema de Palestina, con los reflexivos relatos del pícaro héroe Doha o las boberías del emblemático mulá Nasrudin (Shah, 2000) protagonistas representativos por antonomasia de los chistes en el mundo árabe. La tradición respeta la capacidad de la mujer de engañar al varón (sobre todo, si éste es un marido anciano) pero se trata de artificios y seducciones del sexo femenino reconocidos universalmente. En realidad se trata de un aviso al varón sobre las maldades femeninas. Pero también, y en esto hay una larga tradición desde los cuentos de las 1001 noches, una mujer que ve con mucha más perspicacia que el varón en ciertos momentos y que le avisa de las trampas de otros varones - una consejera desinteresada y compañera frente a falsos amigos.

El nuevo arquetipo que se presenta en las telenovelas difiere sustancialmente de la tradición patriarcalista antifemenina pero se basa en esta versión positiva de Sherezade, porque parte de una autonomía de la mujer que desea realizarse y cumplir una determinada misión, que se sitúa como un elemento moderador o muy crítico de las estructuras patriarcales, sobre todo, la obsesión por el honor o los contratos interclánicos de herencia de solidaridades tribales, ante las que el varón es más débil o tiene menos recursos: el honor es un chantaje constante al varón (Abu-Lughod, 2005).

Ella opone valores nuevos: la familia nuclear frente al clan, el amor frente a la pasión, el acuerdo frente a la venganza... Esta nueva heroína -con gran éxito entre el público femenino por sus ideas y acogida favorablemente entre el público masculino por la belleza de sus actrices- asienta nuevos marcos argumentales que adquieren consistencia en las telenovelas. Asimismo, las propias actrices reales representan un nuevo grupo de figuras femeninas que ocupan el espacio de la prensa del corazón y que tienen una relativa influencia por sus opiniones y manifestaciones públicas (Mosaad, 2002).

\section{La mujer, los blogs y las redes sociales}

Al contrario que en el mundo occidental, mayoritariamente dominado por varones internautas, el mundo árabe ofrece una perspectiva bien diferente: la presencia masiva de mujeres blogueras con una actividad militante intensa y una presencia social activa. Este grupo realiza una producción de gran altura intelectual y con temas 
conflictivos -muchas veces relacionadas con temas relativos a la lucha contra el patriarcalismo-, tratados con una fina ironía. Es un movimiento que no hay que desvincular sino imbricar dentro de un cambio general de la imagen de la mujer en el mundo árabe que rompe los tópicos islamófobos tradicionales.

Dos acontecimientos favorecen esta presencia femenina en la red:

a) La situación más reservada y familiar de la mujer en ciertos países precisamente acentuada en las clases medias y altas- hace que su presencia en el hogar se derive en sus actividades de ocio hacia las nuevas tecnologías.

b) El paro más elevado en el caso de las mujeres licenciadas provoca la presencia de una enorme tropa femenina posesora de cultura elevada en este campo de internautas y aclara el alto nivel intelectual de sus intervenciones.

Ese mundo nocturno de blogueras silenciosas que gritan en la oscuridad de sus ordenadores es una imagen magnífica de un cambio femenino general en el mundo árabe pero no el único. La actividad de cambio ha sido ocultada inconsciente o conscientemente por los medios de comunicación occidentales creando falsas polémicas como la del velo islámico que continuaban una propaganda perversa comenzada a raíz de la intervención en Afganistán.

El caso de Ghada Abdel Aal fue significativo. En 2006 comienza a escribir un blog humorístico ${ }^{1}$ en que relata sus intentos por no casarse con los novios que le buscan su madre y su tía. El blog se convierte en uno de los más leídos de Egipto dando base a un libro y una serie de televisión. La bloguera pasa a ser redactora del diario al-Shorouk y publica su libro 'I want to get married' (Ghada Abdel Aal, 2010) en diversos países.

La presencia de la mujer es menor en los cibercafés pero compensada con una mayor participación desde el hogar. Esto se ha demostrado en el desarrollo previo a las revueltas y en la organización de estas.

\section{La participación de la mujer en las revueltas}

La participación de las mujeres ha sido decisiva desde el principio, estas han estado en el centro de las revueltas pese a que su presencia en los medios de

\footnotetext{
${ }^{1}$ La versión en árabe del blog se puede consultar en http://wanna-b-a-bride.blogspot.com/ y la versión en italiano en: http://cheilvelosiadasposa.blogspot.com/
} 
comunicación tradicionales haya sido mucho menos visible que la de los varones ${ }^{2}$. La base de blogueras siguió actuando y muchas de ellas abandonaron en silencio acogedor de sus cuartos de estudio para incluirse en las manifestaciones en la calle o llevar sus portátiles conectados a los lugares de reunión para informar o introducir videos de denuncia a través de las redes sociales. Habían participado en la preparación del ambiente previo a las revueltas, habían creado sus propias redes sociales y participaron desde el principio.

Puede ser cierto que en algunos casos, las mujeres aparecieran ocasionalmente y se retiraran en momentos de enfrentamiento -era una consigna clara tanto en Túnez como en Egipto en los mensajes de twitter- aunque muchas mujeres decidieron permanecer en la plaza Tahrir a pesar de las amenazas claras de los opositores (los insultos degradantes tildándolas de 'prostitutas' o la amenaza de violación). Pero, también se muestra una tendencia clara y tradicionalmente aceptada por parte de los medios, de olvidar y menospreciar la participación de las mujeres en las protestas y en las guerras. Cuando los medios no muestran las imágenes de las mujeres implicadas en las revueltas, estos conscientemente las están eliminando de la construcción de la sociedad futura y de la explicación de la historia.

Por otro lado, la participación y coordinación de la información ha tenido una enorme participación femenina, pese a que fuera menos evidente que la de los blogueros públicos (aunque en la plaza Tahrir fueron bien visibles), a la hora de las decisiones, las profesionales femeninas de los colectivos de derechos humanos se impusieron a sus compañeros varones.

Una de las mujeres más destacadas en esta transformación del espacio público ha sido la joven estudiante tunecina Leena Ben Mhanni, que desde las redes sociales y especialmente desde su blog "A Tunisian girl”, , donde subraya que la censura de su país no le permite expresarse, alentó desde el principio a la población a manifestarse. Además de su blog que ha sido visitado por más de 100.000 personas de todos los países, su perfil de twitter, con 3261 seguidores, y de Facebook con 19.000 seguidores,

\footnotetext{
${ }^{2}$ La falta de visibilización de las mujeres en las revueltas por parte de los medios de comunicación tradicionales fue confrontado desde las redes sociales, donde diversas usuarias se dedicaron a recopilar imágenes donde se podía ver a las mujeres árabes participando en las movilizaciones. Algunos ejemplos pueden encontrarse en https://www.facebook.com/ album.php?id=586357675\&aid=268523 y en http://www.sawtalniswa.com/2011/02/women-ofthe-egyptian-revolution/. También el diario "Le Monde" subrayó en su edición digital del 29 de enero de 2011 su admiración por la participación de las mujeres en la revolución tunecina: http://www.lemonde.fr/international/portfolio/2011/01/29/tunisie-l-heroisme-ordinaire-desfemmes_1472219_3210.html

${ }^{3}$ http://atunisiangirl.blogspot.com/
} 
se han convertido en espacios de movilización, reflexión y análisis sobre la situación de las poblaciones árabes, sus reivindicaciones democráticas y su participación en las revoluciones actuales.

Lenna Ben Mhanni deja claro en el lema de su blog, su implicación en las revueltas desde una postura feminista y de lucha por los derechos de las mujeres: "Anyone who knows anything of history knows that great social changes are impossible without feminine upheaval. Social progress can be measured by the social position of the female sex"4. En Egipto, una de las mujeres que participó más activamente en la organización de las revueltas fue Asmaa Mahfouz, de 26 años, licenciada en Administración de Empresas por la Universidad del Cairo y una de las impulsoras del grupo de facebook "Movimiento juvenil del 6 de abril"" .

Mahfouz colgó un video ${ }^{6}$ en su perfil de facebook y en youtube el 18 de enero de 2011, donde pedía que la población egipcia saliera a la calle a reclamar el fin del régimen corrupto de Hosni Mubarak y principalmente a defender los derechos humanos. En este especificaba concretamente que era una chica y que no tenía miedo y espetaba a los hombres a ser igual de valientes que ella: "Si crees que eres un hombre, ven conmigo el 25 de abril". El video rápidamente fue difundido por todas las redes sociales e intercambiado por teléfonos móviles y la autora ha sido entrevistada por diversas televisiones y periódicos internacionales.

Ben Mhanni y Mahfouz son sólo representantes de las miles de mujeres que participaron en estas revueltas desde todas las posiciones. Pese a que en el pasado más reciente también habían existido activistas mujeres en los países árabes, como es el caso de Israa Abdel Fattah ${ }^{7}$, estas nunca habían conseguido la movilización masiva de

\footnotetext{
${ }^{4}$ Traducción de los autores: "Cualquiera que conozca un poco de historia sabe que los grandes cambios sociales son imposibles sin la agitación y transformación femenina. El progreso social puede ser medido por la posición social de las mujeres". http://atunisiangirl.blogspot.com/

${ }_{5}^{5}$ Grupo con más de 100.000 miembros, principalmente jóvenes licenciados y licenciadas de Egipto, que nació en 2008 para apoyar a un colectivo de trabajadores egipcios en huelga y que se convirtió rápidamente en un espacio de debate y de defensa de los derechos democráticos: http://www.facebook.com/group.php?gid=9973986703\&v=wall

${ }^{6} \mathrm{http}: / / \mathrm{www}$.youtube.com/watch?v=SgjIgMdsEuk . Es destacable que Mahfouz aparezca con velo en este video, al igual que la mayoría de las otras mujeres que se han movilizado. Esto muestra que la cuestión del velo es mucho más compleja de lo que se deduce a partir de la polémica creada desde los medios occidentales.

${ }^{7}$ Israa Abdel Fattah es una bloguera y activista por los derechos humanas egipcia cofundadora del "Movimiento juvenil del 6 de abril", fue arrestada en abril de 2008 y se convirtió en una figura de resistencia por la prensa internacional pasando a ser llamada "Facebook girl". Estuvo durante un tiempo retirada hasta que reapareció en las protestas de enero de 2011, a parte de la difusión de la revuelta en Internet también aportó información e imágenes de los grupos de oposición a la dictadura en la cadena de televisión al-Jazira.
} 
mujeres que se ha dado en las revueltas de Túnez, Egipto y otros países árabes durante el periodo 2010-2011. En este contexto, también ha destacado el movimiento de las madres cuyos hijos fueron asesinados por la policía en este periodo. La madre del bloguero Khaled Said, (asesinado a golpes por la policía en junio de 2010 en un cibercafé cuando pretendía publicar un video de protesta en Internet y cuya muerte desencadenó múltiples protestas en Egipto), creó una página en facebook "We are all Khaled Said" con más de 100.000 miembros, donde se denunciaban los casos de tortura, violencia y corrupción de la policía y de la dictadura egipcia, y se reclamaba la instauración de una democracia.

Como hemos explicado, pese al intento de invisibilizarlas por parte de los medios de comunicación, las mujeres han sido una parte vital de las revoluciones recientes en el mundo árabe. Las estimaciones realizadas por las organizaciones de derechos humanos, sitúan su participación entre el 20\% y el 50\% (Jenna Krajeski, 2011). Esta participación sin precedentes, donde las mujeres árabes se exponen a ser arrestadas junto a los hombres y a situaciones de violencia clara, es posible gracias a todos los detalles que hemos apuntado en este artículo, principalmente los cambios paulatinos en los medios de comunicación ofreciendo la imagen de una nueva mujer, las redes sociales que han permitido la unión de diferentes grupos de protesta, la organización pacífica de la protesta y el cambio generacional con grupos de jóvenes, hombres y mujeres, educados en las universidades que han visto que las dictaduras no les ofrecen ningún futuro.

El éxito de la revuelta en Túnez mostró como el cambio no era una utopía, lo que dio fuerza a la revolución posterior de Egipto e incrementó también el número de mujeres en este espacio público de representación y movilización.

\section{Conclusiones}

La preparación de este nuevo mundo árabe juvenil y ansioso de cambiar la situación político-social de sus sociedades ha contado con una gran participación femenina y no sería comprensible sin esta contribución en un plano de igualdad. Este cambio ha sido preparado por la variación de la imagen de la mujer preparada por los medios tradicionales (películas y novelas, programas de televisión de ficción y

\footnotetext{
${ }^{8}$ http://www.facebook.com/elshaheeed.co.uk
} 
entretenimiento), por las redes satelitales (presentadoras y programas de debate), finalmente, por los blogs y las redes sociales desde hace cinco años.

Esta contribución ha sido fundamental en el mundo de los blogs que prepararon el escenario previo a las revueltas y ha sido determinante en la organización del flujo de la información durante estas revueltas. Esta nueva usuaria-creadora dentro del panorama mediático responde a una mentalidad también novedosa y correspondiente a un espacio deliberativo individualista pero solidario (formado por las opiniones que se expresan en los blogs y las nuevas redes sociales).

\section{BIBLIOGRAFÍA}

- Abu-Lughod, L. (1995): "The objects of soap opera: Egyptian television and the cultural politics of modernity”. En Miller D. (ed.) Worlds Apart: Modernity Through the Prism of the Local. London: Routledge, pp.190-210.

- Abul-Magd, Z. P. A. E. (2006): Research Cultures in Local and Global Contexts: The Case of middle East Gender Studies. Georgetown University: Center for Contemporary Arab Studies.

- Alavi, N. (2005): We Are Iran: The Persian Blogs by Nasrin Alavi Brooklyn: Soft Skull Press.

- Armbrust, W. (1998): “Transgressing Patriarchy: Sex and Marriage in Egyptian Film”. En Middle East Report (MERIP), n. 206 (Spring), pp. 29-31.

- Chaker, A. (2004): Genre et éducation, Feminin-Masculin. La marche vers l'égalité au Maroc, 1993-2003. Rabat: Fondation Freidrich Ebert.

- Eickelman, D. F. y Anderson, J. W. (eds.) (1999): New Media in the Muslim World: The Emerging Public Sphere. Bloomington: Indiana University Press.

- El-Nawawy, M. y Iskandar, M. (2007): Al-Jazeera: How the Free Arab News Network Scooped the World and Changed the Middle East. Colorado: Westview Press.

- Fargues, P. H. (2003): "La femme dans les pays arabe: vers une remise en cause du système patriarcal?. En Bulletin Mensuel information INED, Population \& Sociétés, $\mathrm{n}^{\circ}$. 387, Dosier completo.

- Fauad, W. (2010): "Facebook y la juventud árabe. ¿Activismo social o liberación cultural?". En AWRAQ. Revista de análisis y pensamiento sobre el mundo árabe e islámico contemporáneo, $\mathrm{n}^{\mathrm{o}} .2 \mathrm{pp} .61-78$

- Ghada Abdel Aal, (2010): I Want to Get Married!: One Wannabe Bride's Misadventures with Handsome Houdinis, Technicolor Grooms, Morality Police, and 
Other Mr. Not Quite Rights (Emerging Voices from the Middle East). Austin: Center for Middle Eastern Studies, University of Texas at Austin.

- Hadan, A. (2005): "Women and education in Saudi Arabia: challenges an Achievements", International Education Journal. no. 6 (1), pp.42-64.

- James, L. M. (2006): “Whose Voice? Nasser, the Arabs, and 'Sawt al-Arab' Radio”. En TBS Transnational Broadcasting Studies, $\mathrm{n}^{\circ}$. 16 [en línea] Disponible en: http://www.tbsjournal.com/James.html [25/02/2011].

- Kraidy, M. M. (2002): “Arab Satellite Television Between Regionalization and Globalization". En Global Media Journal no1 (1) [en línea] Disponible en: http://lass.calumet.purdue.edu/cca/gmj/OldSiteBackup/SubmittedDocuments/archivedp apers/fall2002/kraidy.htm [23/02/2011].

- Krajeski, J. (2011): "Women Are a Substantial Part of Egyptian Protests". En: Slate [en línea] Disponible en: http://www.doublex.com/blog/xxfactor/women-aresubstantial-part-egyptian-protests [23/02/2011]

- Labidi, K. (2003): “The Voice of the Arabs is Speechless at 50”. En The Daily Star, 07 de octubre de 2003.

- Lamloum, O. (2006): Al-Jazira. Espejo rebelde y ambiguo del mundo árabe. Barcelona, Hacer E.

- Mosaad, M. (2002): “Knight without a Horse: The Lesson is Over Stupid! Racism versus rationality in Egyptian society". En Viewpoints/PeaceWatch, December 5.

- Nisbet, E.; Nisbet, M.; Scheufele, D. y Shanahan, J. (2004): "Public diplomacy, television news, and Muslim opinion". En: Harvard International Journal of Press/Politics n'. 9 (2), pp. 11-37.

- Perceval, J. M., (2007): "Entre el humor i el furor: sàtira i visió d'Occident en el mitjans de comunicació del món arabo-musulmà”. En Quaderns del CAC: Consell Audiovisual de Catalunya, $\mathrm{n}^{\circ}$. 27, pp. 37-45.

- Shah, I. (2002): Las ocurrencias del increíble Mulá Nasrudin. Barcelona: Paidós.

- Stratton, A. (2009) Muhayababes. Chicas con velo. El nuevo oriente Próximo: joven, cool y devoto. Madrid : 451 editores.

- Taureg, M. y Wittmann, F. (eds.) (2005): Entre tradition orale et nouvelles technologies: où vont les mass média au Sénégal?. Dakar: Enda Tiers Monde. 